Supporting information-Jp076552m

\title{
Supramolecular Zinc Phthalocyanine-Perylene Bisimide Triad: Synthesis and Photophysical Properties
}

\author{
Yu Chen, ${ }^{\text {a,* }}$ Ying Lin, ${ }^{\text {a }}$ Mohamed E. EI-Khouly, ${ }^{*, b, c}$ Xiaodong Zhuang, ${ }^{\text {a }}$ Yasuyuki \\ Araki, *, ${ }^{\mathrm{b}}$ Osamu Ito, ${ }^{\mathrm{b}}$ and Weian Zhang ${ }^{\mathrm{a}}$ \\ ${ }^{a}$ Laboratory for Advanced Materials, Department of Chemistry, East China University of \\ Science and Technology, 130 Meilong Road, Shanghai 200237, People's Republic of \\ China; Email: chentangyu@yahoo.com \\ ${ }^{b}$ Institute of Multidisciplinary Research for Advanced Materials, Tohoku University, \\ Katahira 2-1-1, Aoba-ku, Sendai, 980-8577 Japan; Email: araki@tagen.tohoku.ac.jp \\ ${ }^{c}$ Department of Chemistry, Faculty of Education, Tanta University, Egypt; Email: \\ mohamedelkhouly@yahoo.com
}

\section{General}

All chemicals were purchased from Aldrich and used without further purification. Organic solvents were purified, dried and distilled under dry argon. The operations for synthesis prior to the termination reaction were carried out under purified argon. The UV/Vis spectral measurements were carried out with a JASCO model V570 DS spectrophotometer. Steady-state fluorescence spectra were measured on a Shimadzu RF5300 PC spectrofluorophotometer equipped with a photomultiplier tube having high sensitivity in the $700-800 \mathrm{~nm}$ region. The sample for the fluorescence measurement was dissolved in the dry toluene or benzonitrile, filtered, transferred to a long quartz cell, and then capped and bubbled with high pure argon(without $\mathrm{O}_{2}$ and moisture) for at least 15 minutes before measurement. MALDI-TOF-MS measurements were performed on a Bruker REFLEX III-S (preparation method of sample: the samples were dissolved in dry THF, then mixed 1:1 (0.8 $\mu \mathrm{l}$ each) with a methanol solution of $\alpha$-cyano-4hydroxycinnamic acid as matrix); Elemental Aanalyses: Carlo-Erba Elemental Analyser 
1104, 1106. ${ }^{1} \mathrm{H}-\mathrm{NMR}$ and ${ }^{13} \mathrm{C}$-NMR spectra were performed on a JEOL LAMBDA 400 $\left(\mathrm{CDCl}_{3}\right.$ as solvent); Analytical thin layer chromatography (TLC) was performed using aluminium coated Merck Kiesegel 60254 plates.

The redox values were measured using the differential pulse voltammetry (DPV) technique by applying BAS CV-50W Voltammetric Analyzer (Japan). A platinum disk electrode was used as working electrode, while a platinum wire served as a counter electrode. $\mathrm{An} \mathrm{Ag} / \mathrm{AgCl}$ electrode was used as a reference electrode. All measurements were carried out in different solvents containing $0.1 \mathrm{M}$ tetra-butylammonium percholarate $\left[(n-\mathrm{Bu})_{4} \mathrm{NClO}_{4}\right]$ as a supporting electrolyte. The scan rate used is $0.1 \mathrm{~V} \mathrm{~s}^{-1}$.

Nanosecond-transient absorption measurements were carried out using third harmonic generation (THG, $355 \mathrm{~nm}$ ) of an Nd:YAG laser (Spectra-Physics, Quanta-Ray GCR-130, $6 \mathrm{~ns}$ FWHM) as an exciting source. For transient absorption spectra in the near-IR region (600-1400 nm), monitoring light from a pulsed Xe-lamp was detected with a Geavalanche photodiode (Hamamatsu Photonics, B2834). For transient absorption spectra in the visible and near-IR region (400-1000 nm), monitoring light from a pulsed Xe-lamp was detected with a Si-PIN photodiode (Hamamatsu Phonics, S1722-02). 


\section{Spectral characterization data}

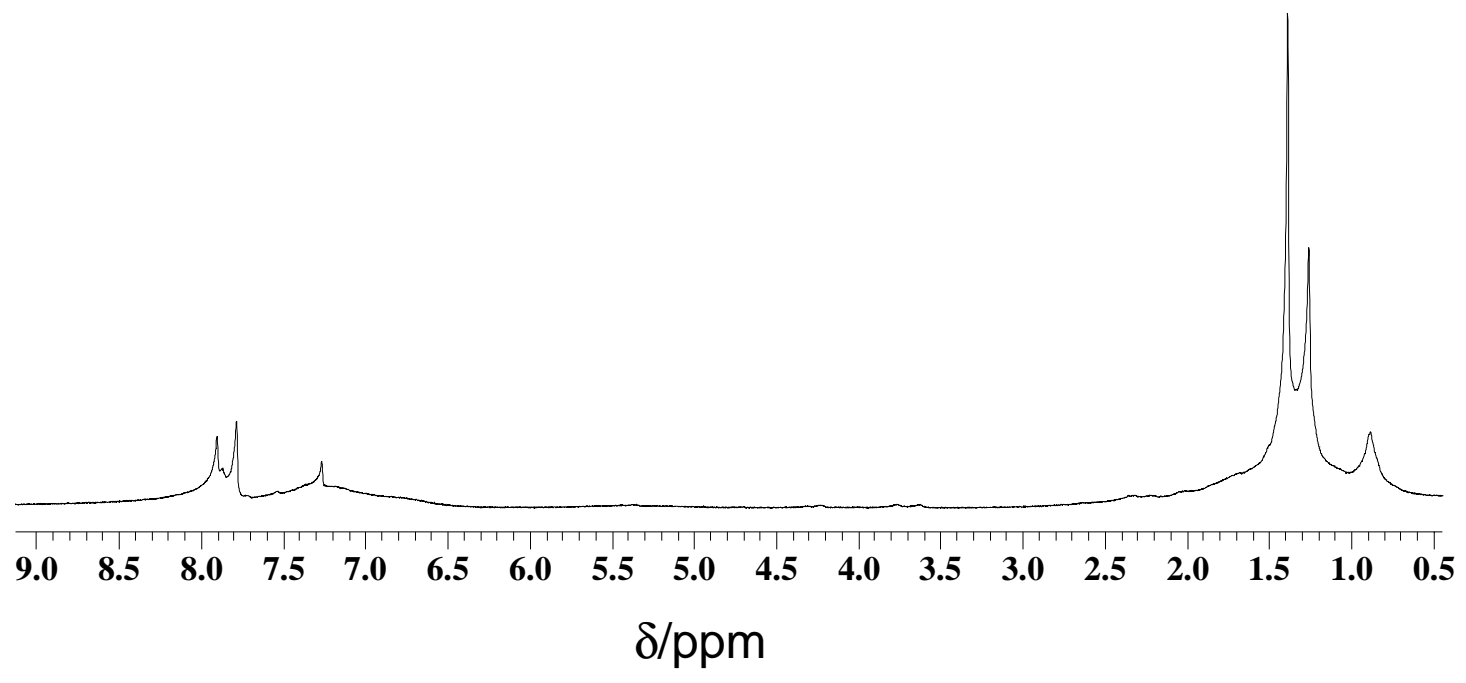

Figure S1. ${ }^{1} \mathrm{H}-\mathrm{NMR}$ spectrum of $\mathrm{PcZn}-\mathrm{Pim}-\mathrm{PcZn}$ triad in $\mathrm{CDCl}_{3}$. Due to strong aggregation effect exhibited by this triad in solution, the observed proton signals are broadened significantly.

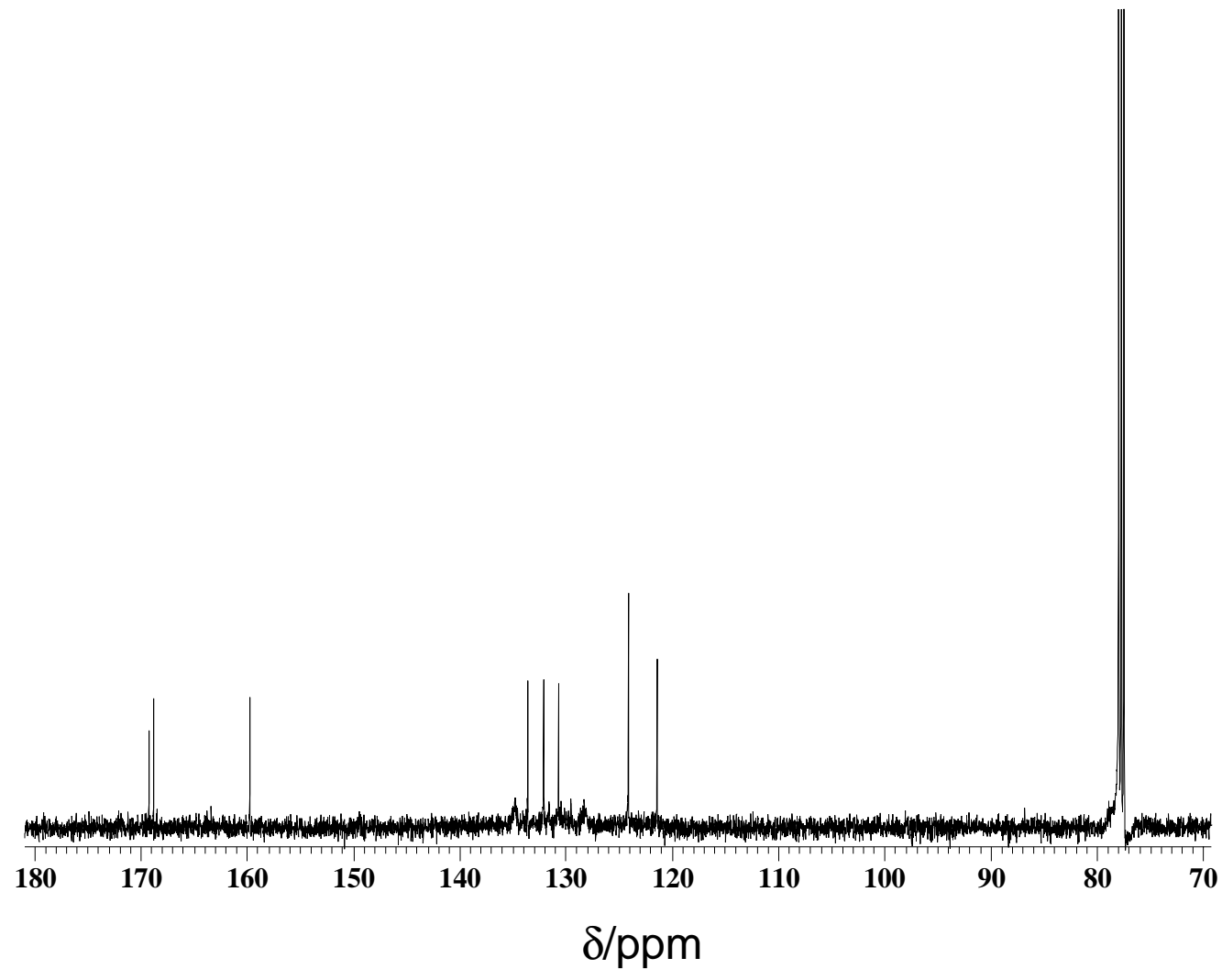

Figure S2. ${ }^{13} \mathrm{C}-\mathrm{NMR}$ spectrum of $\mathrm{PcZn}-\mathrm{Pim}-\mathrm{PcZn}$ in $\mathrm{CDCl}_{3}$. 


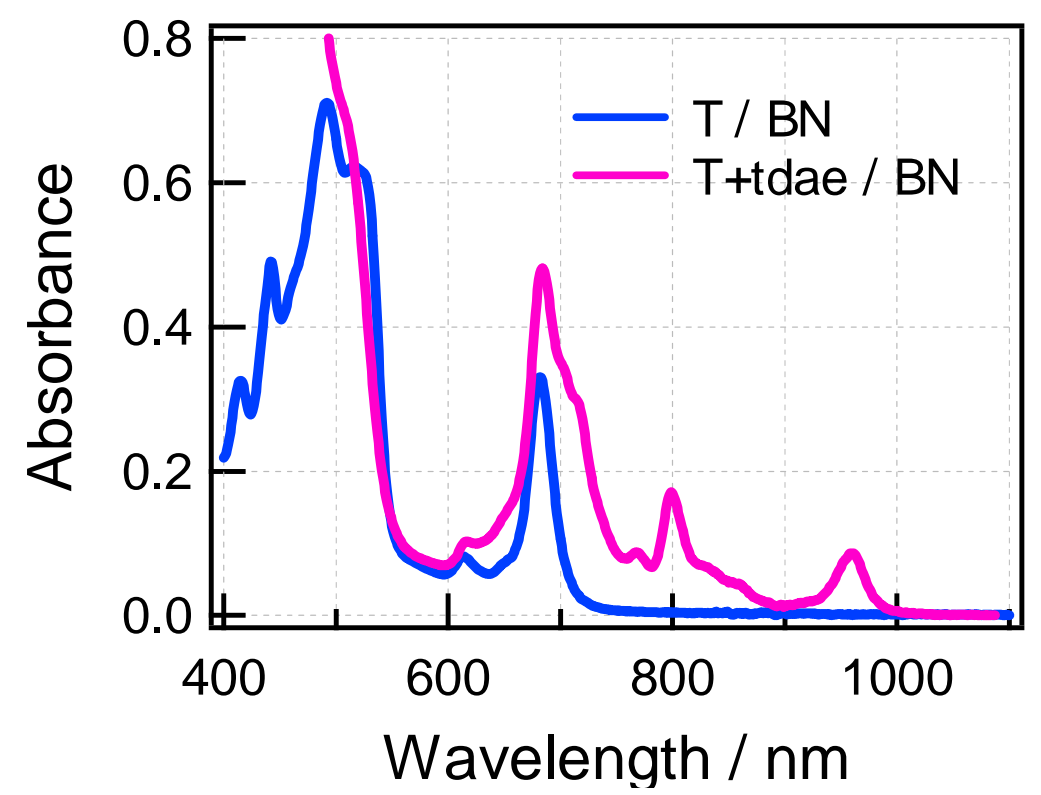

Figure S3. Absorption spectra of PcZn-Pim-PcZn (T) in the presence of tetrakis(dimethylamino)ethylene (TDAE) in benzonitrile.

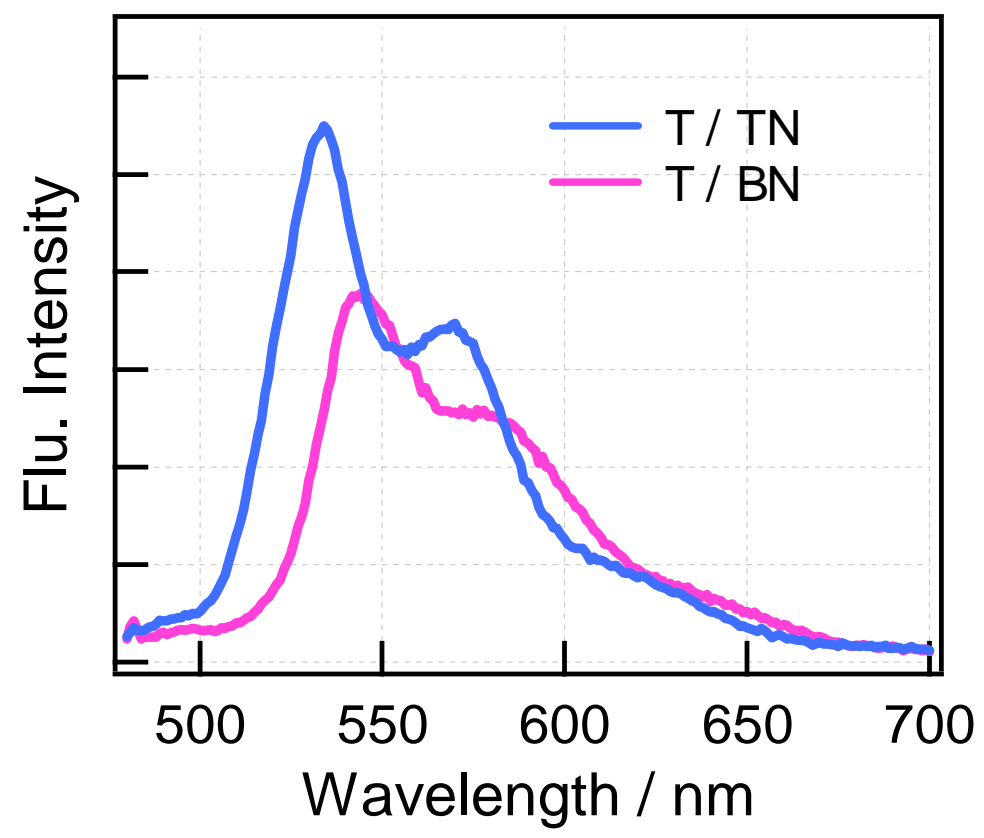

Figure S4. Steady-state fluorescence spectra of PcZn-Pim-PcZn triad $\left(\mathrm{T}, 2 \times 10^{-5} \mathrm{M}\right)$ in benzonitrile and toluene. $\lambda_{\mathrm{ex}}=480 \mathrm{~nm}$. 


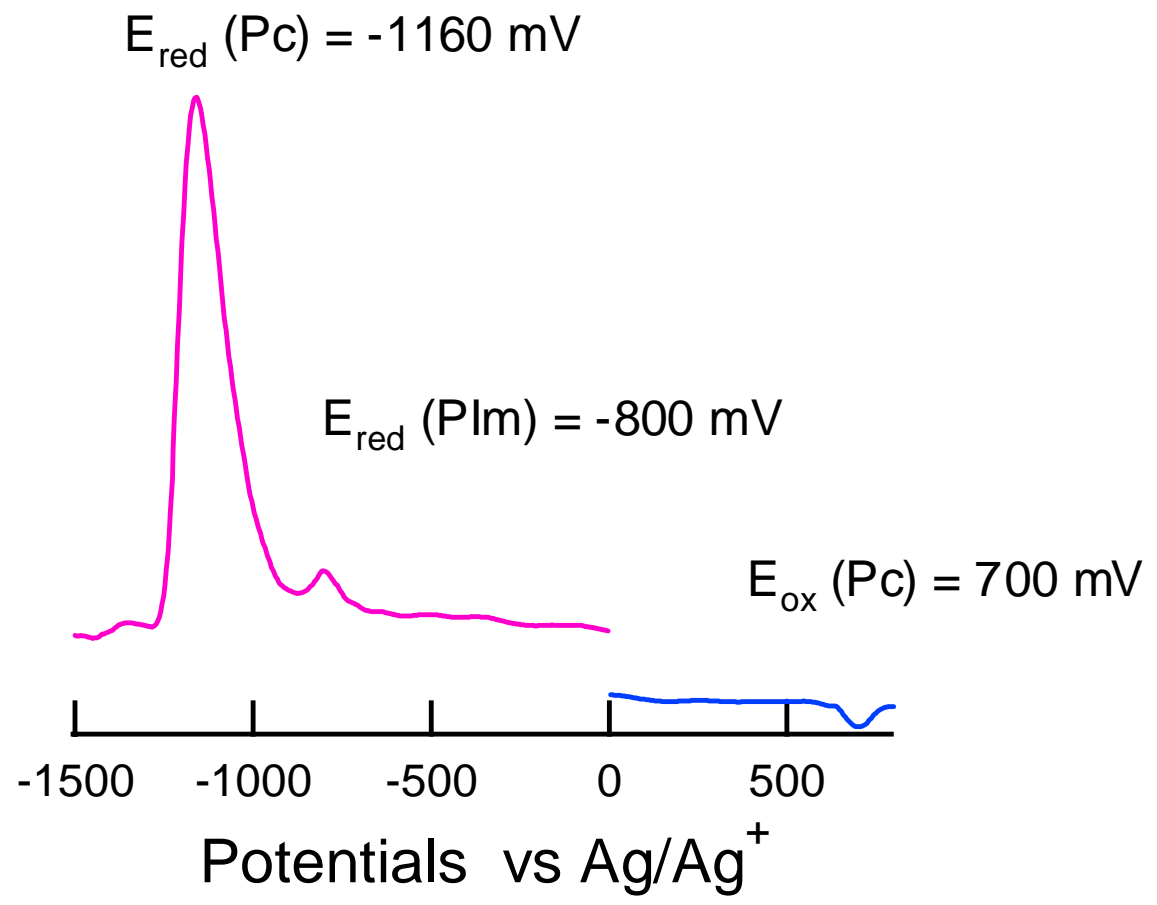

Figure S5. The redox potentials of PcZn-Pim-PcZn triad in benzonitrile by applying differential pulse voltammetry technique. 

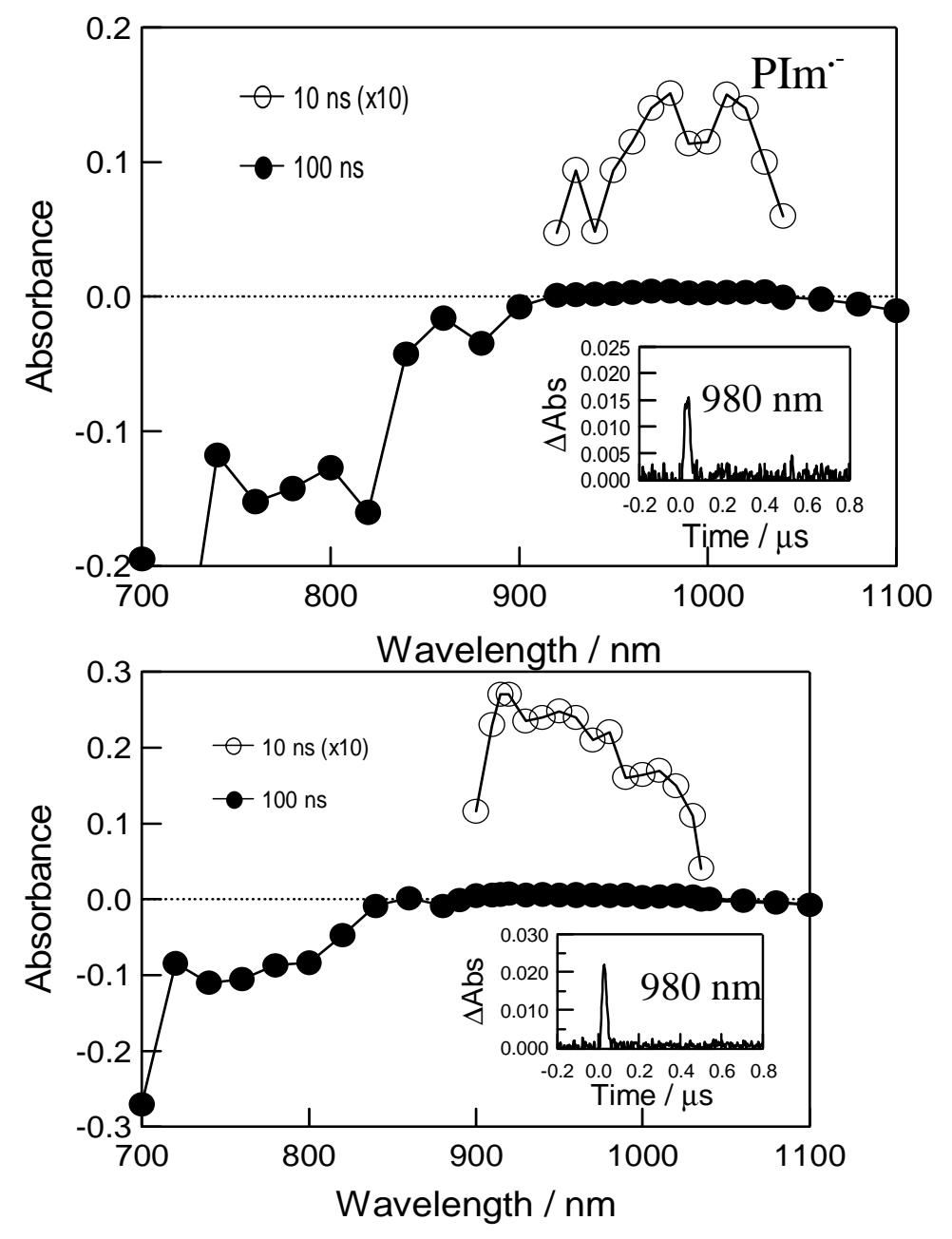

Figure S6. Transient absorption spectra obtained by $532 \mathrm{~nm}$ laser light of PcZn-Pim-PcZn triad; (upper panel) in argon-saturated toluene and (Lower panel) in benzonitrile. Inset: time profiles. 